\title{
EL FRAUDE ADUANERO EN LA INDUSTRIA TEXTIL ECUATORIANA, PERÍODO 2010-2015
}

\author{
CUSTOMS FRAUD IN THE ECUADORIAN \\ TEXTILE INDUSTRY, PERIOD 2010-2015
}

\section{DARWIN ROSALES NIETO}

Universidad Tecnológica Equinoccial

Correo electrónico: darwin.rosales@ute.edu.ec

\section{LAURA DE LA CRUZ GUERRERO}

Universidad Tecnológica Equinoccial

Correo electrónico: laura.delacruz@ute.edu.ec

DANIEL GALEFSKI PASTENES

Universidad Tecnológica Equinoccial

Correo electrónico: gpda48822@ute.edu.ec

MILENA FERNÁNDEZ HERNÁNDEZ

Asociación de Industriales Textiles del Ecuador - AITE $\quad$ FeCHa DE RECEPCIÓN: 05/05/2016

Correo electrónico: milefer23@hotmail.com

FECHA DE ACEPTACIÓN: 05/06/2016

\begin{abstract}
RESUMEN
Desde la época de la Colonia, la habilidad por los hilados se hizo notoria en la población, especialmente de la sierra ecuatoriana; esta habilidad se ha desarrollado hasta alcanzar niveles de industrialización y es así que esa industria, que tradicionalmente se caracterizó por fabricar hilados y tejidos, en las dos últimas dos décadas ha experimentado un crecimiento en el área de la confección de prendas de vestir, la que ha alcanzado niveles importantes de producción a base de la incorporación de tecnología, diseños modernos y búsqueda de mercados externos; sin embargo, los altos costos de producción, la competencia de productos extranjeros que no siempre ingresan al país cumpliendo todas las formalidades aduaneras, son entre otros factores, limitantes del desarrollo de una industria que es generadora de plazas de trabajo y de riqueza para el país. Este segundo aspecto, el del fraude aduanero en la industria textil ecuatoriana, es abordado en este documento, desde un análisis de las estadísticas de los últimos años, más el aporte que como resultado de la experiencia de los autores, que han trabajado varios años en la Aduana del Ecuador, permite una visión más objetiva del tema estudiado.
\end{abstract}

Palabras clave: Control aduanero, fraude aduanero, industria textil. 


\begin{abstract}
Since colonial times, threading has been notorious in the population of Ecuadorian highlands. This skill has been developed to the point of industrialization and in the last two decades it has grown in the clothing sector, also reaching important levels of production based on the inclusion of new technology, modern designs and external markets. However, high production costs, competition from foreign products that don't always comply with customs regulations, among other factors, have limited the development of an industry that creates job opportunities and wealth. Customs fraud in the Ecuadorian textile industry is the subject of this document, starting from a statistical analysis from the recent years, plus the contribution based on the experience from the authors who have worked several years in the Ecuadorian Customs service, allowing a more objective vision on the subject.
\end{abstract}

Keywords: Custom control, customs fraud, textile industry.

\section{Introducción}

La industria textil ecuatoriana tiene sus antecedentes en la época de la colonia, donde la habilidad de los indígenas, especialmente de la serranía ecuatoriana, daba forma a la lana de oveja, transformándola en vestuario que era utilizado en los hogares de la época. Pedro Pinto Rubianes relata en el libro de la Asociación de Industriales Textiles del Ecuador (AITE 1, 2011) que las primeras industrias textiles en el país se constituyeron en el año de 1832 donde se fabricaban tejidos de lana que eran llevados a Colombia, hasta que:

La producción textil en el Ecuador inició su desarrollo con la aparición de las primeras industrias que en un principio se dedicaron al procesamiento de lana, hasta que a inicios del siglo XX se introdujo el algodón; material que impulsó la producción hasta la década del 50 , momento en el que se consolidó la utilización de esta fibra. (PROECUADOR, 2012).

Hoy por hoy la industria textil ecuatoriana es una de las principales generadoras de empleo, tanto a nivel profesional, técnico y especialistas, el porcentaje más alto es la mano de obra no calificada que interviene en las diferentes fases del proceso, llegando a ser el segundo sector manufacturero que más mano de obra emplea, después del sector de alimentos, bebidas y tabacos. Según estimaciones hechas por la Asociación de Indus- triales Textiles del Ecuador - AITE, "representa el $8 \%$ del total de la industria nacional y genera 100.000 empleos directos, y 200 mil indirectos. Además el $70 \%$ es de mujeres que trabajan en el área textil son cabeza de familia" (AITE 2, 2016). Es también un espacio de oportunidades por la demanda de insumos que provienen del sector ganadero, agrícola, químico, etc. Sin embargo, esta industria ha recibido el impacto de la competencia desleal que mediante diferentes artificios perjudica no solo a esta industria, sino al Estado y al país en general. Para analizar este aspecto es necesario definir el FRAUDE, que "el acto contrario a la verdad y a la rectitud, tendiente a eludir una disposición legal en perjuicio del Estado o de terceros. Comprende la infracción y el delito" (CAN 4, 2007). Por lo que se colige que fraude aduanero es cualquier infracción o delito que se produce como resultado de violentar la leyes o reglamentos que rigen la actividad aduanera o tributaria.

(CAN 4, 2007) considera que las manifestaciones más significativas de fraude aduanero son:

a) La subvaluación

b) La sobrevaluación

c) Falsedad de origen

d) Acogimiento indebido a una menor tasa

e) Contrabando

f) Acogimiento indebido a un beneficio o exoneración tributaria

g) Prácticas de competencia desleal 
Las etapas en las cuales se puede cometer fraude

a) Fraude antes o previo a la nacionalización de la mercancía

b) Fraude durante o concurrente a la nacionalización de la mercancía

c) Fraude posterior a la nacionalización de la mercancía

Javier Díaz (2012, párr. 6), presidente ejecutivo de la Asociación de Industriales Textiles del Ecuador (AITE), manifiesta que la industria textil ecuatoriana ha consolidado sus ventas al mercado interno, pero siempre ha tenido una visión exportadora, ha realizado inversiones en maquinaria y tecnología para tratar de estar a la vanguardia de tal manera que puedan competir en mercados internacionales con productos de excelente calidad y durabilidad. Sin embargo, se enfrenta al reto de competir dentro y fuera del país en condiciones que no son las más favorables, pues a los altos costos de producción, se suman factores como el contrabando que:

Consiste en introducir o sacar mercancías de un país infringiendo las leyes y los reglamentos o medidas de prohibición y restricción o para eludir o tratar de eludir las ventas y tasas aplicables sin llenar la declaración aduanera o para evitar los controles. (CAN 4, 2007)

De este ilícito se conoce que grandes cantidades de ropa que intentaban ingresar al país han sido aprehendidas, pese a ello, las incautaciones aún son mínimas respecto de lo que se sospecha. "Creemos que al menos es unas 10 veces más lo que circula en el mercado de ropa contrabandeada”...Hoy, las importaciones suman unas 10000 toneladas, por lo que hay un hueco de 14000 toneladas. ¿Quién cubrió eso? Los industriales ecuatorianos no tienen la capacidad para cubrirla; acaso unas 7000 toneladas. Y, ¿el resto? Se presume que es contrabando" (EL COMERCIO, 2014). Otra modalidad es la subvaloración que consiste en "rebajar dolosamente el valor de una mercancía con la finalidad de reducir la base imponible y con ello obtener una liquidación menor a la que legalmente estaría afecta su ingreso al país" (CAN 4, 2007, pág. 18). Al respecto, existen versiones como las de Javier Díaz, Presidente de la AITE, según quien "mientras hay importadores que declaran, por ejemplo, USD 60 por kilogramo, otros lo hacen en USD 5" (EL COMERCIO, 2014). Existen otras modalidades de ingreso de textiles y de ropa confeccionada al país como el sistema de Courier, especialmente en las categorías $\mathrm{B}$ y $\mathrm{D}$ que son mal utilizadas y que se suman a las formas de ingreso fraudulento de mercancías al país.

En un balance general,

La compleja situación macroeconómica que atraviesa el Ecuador se traslada rápidamente a los negocios, a la microeconomía, al sector privado. Para la industria textil y confección ecuatoriana este fenómeno ocurre desde 2012, año en el cual cayó un 7,67 por ciento en su Producto Interno Bruto (PIB) real frente al año inmediatamente anterior. En 2013 y 2014, según las mismas cifras, el sector creció 3,28 y 2,92 por ciento, pero hasta el tercer trimestre de 2015 vuelve a tener un decrecimiento de 2,64 por ciento.

Las exportaciones textiles en 2015 hasta octubre tuvieron una caída cercana al 30 por ciento frente al mismo mes del 2014. En 2016 el panorama no parece tener visos de mejora. (VISTAZO, 2016).

La solución a este problema necesita de una estrategia de lucha contra el fraude en la industria textil que a los problemas señalados incluya temas de propiedad intelectual y de defensa del consumidor, de tal forma que se logre un cambio de comportamiento de todos los involucrados de este sector productivo.

El marco legal para respaldar esa estrategia existe, pues la Constitución de la República en los artículos 319 y 320 contempla que:

El Estado promoverá las formas de producción que aseguren el buen vivir de la población y desincentivará aquellas que atenten contra sus derechos o los de la naturaleza; 
alentará a la producción que satisfaga la demanda interna y garantice una actividad participación del Ecuador en el contexto internacional. La producción, en cualquiera de sus formas, se sujetará a principios y normas de calidad, sostenibilidad, productividad sistémica, valoración del trabajo y eficiencia económica y social. (Tribunal Constitucional, 2008, pág. 56)

A lo que se suman diferentes cuerpos legales y reglamentarios que regulan la actividad textil, a saber: Código Orgánico de la Producción, Comercio e Inversiones; Código Orgánico Integral Penal; Ley de Gestión Ambiental; Ley de Régimen Tributario Interno; Ley del Sistema Ecuatoriano de Calidad; Ley de Comercio Exterior e Inversiones; Ley Orgánica del Sistema Nacional de Contracción Pública; Reglamento Técnico del INEN; Registro de Importadores.

El presente estudio presenta cifras y criterios acerca del impacto que el fraude aduanero genera en la industria textil del país, corresponderá a las autoridades aplicar las medidas para combatir estas prácticas ilegales y así reducir los efectos en un sector que aporta de manera importante para el desarrollo del país.

\section{Metodología}

En el desarrollo de este estudio se utilizaron estadísticas del Banco Central del Ecuador, datos publicados por el Servicio Nacional de Aduana del Ecuador en sus informes de gestión, los cuales han sido analizados y complementados con otras fuentes con el fin de obtener una visión amplia y objetiva del tema estudiado. Los boletines de la
Asociación de Industriales Textiles del Ecuador, AITE, han sido fuente de consulta, especialmente para conocer el criterio de quienes son actores claves en este sector de la economía ecuatoriana. El fundamento teórico ha sido extraído de los documentos que contienen la norma legal que regula el comercio exterior ecuatoriano y también de la normativa regional, que bajo el principio de supranacionalidad es parte del quehacer comercial y económico del país.

Ha sido un interesante ejercicio desarrollado alrededor de la teoría y de la práctica, una combinación del análisis de fuentes primarias y secundarias, apoyadas en métodos inductivos y deductivos que se han complementado con lo aprendido en años de trabajo en la empresa pública y privada que otorgan a los autores una modesta experiencia que hemos procurado plasmarla en este documento.

\section{Resultados}

\section{Importaciones textiles}

Es importante conocer que la palabra tela comprende a los tejidos que son elaborados partiendo de su materia prima correspondiente sean estos el algodón, poliéster, etc.

Además, las prendas de vestir son todos los artículos fabricados con un sinnúmero de telas utilizados por los seres humanos para cubrir el cuerpo en general.

Finalmente es necesario conocer que la ropa de hogar son todas las prendas tales como sabanas, cobijas, cobertores y sus similares. 
Figura 1. IMportaciones de telas SEgún SU ORIGEN De ENERO A DiCiembre de 2015. Miles de dólares

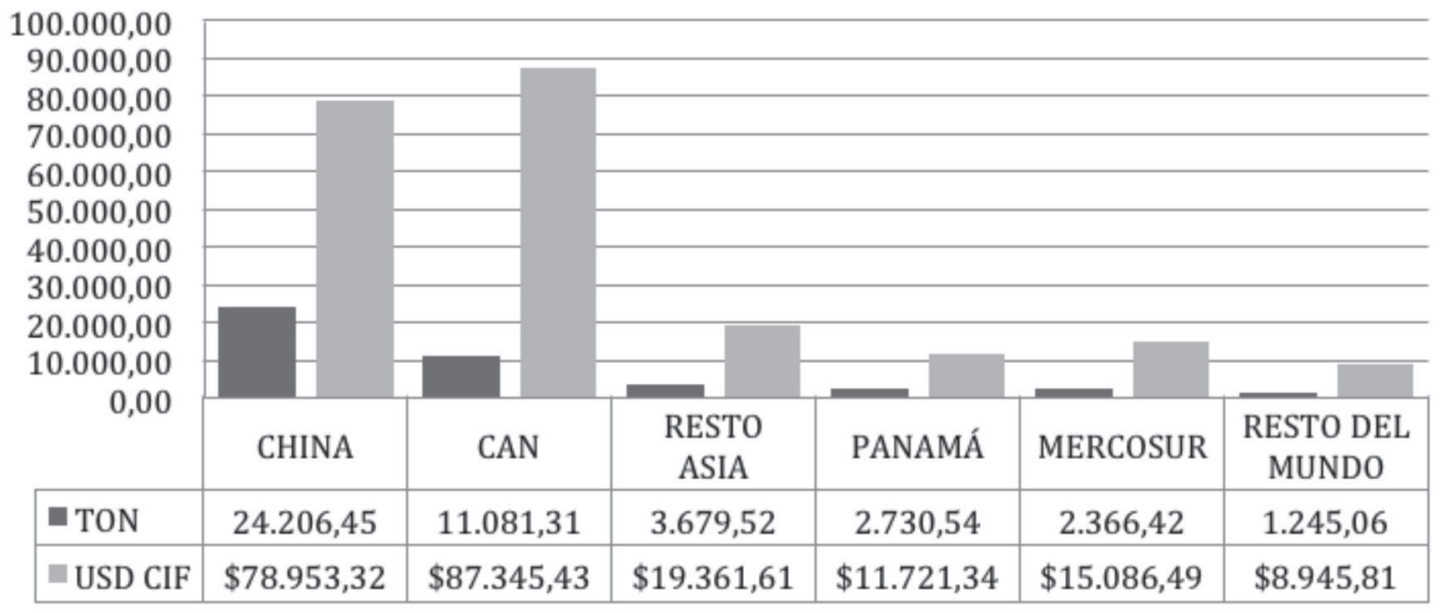

Fuente: BCE

En la figura $\mathrm{N}^{\circ}$. 1 se observa que el $53 \%$ de las telas importadas por Ecuador provienen de China, su valor promedio por kilo es de US $\$ 3,26$. La Comunidad Andina es el siguiente sector desde la cual provienen telas importadas, y aunque se convierte en el segundo proveedor con un $25 \%$ de participación, es evidente la brecha en relación con el porcentaje de tela originaria de China; también es notoria la diferencia en el promedio de precios, pues la tela proveniente de la CAN ingresa a US $\$ 7,88$ por kilo y el resto de tela importada procede de otros lugares como Panamá,
MERCOSUR, con precios promedio por kilo de US \$ 4,29 y US \$ 6,38 respectivamente.

Una primera observación de estos datos nos permite apreciar la gran diferencia entre los precios promedio por kilo de tela importada desde la China, que acapara más del $50 \%$ del mercado ecuatoriano con relación al resto de proveedores, de lo que se colige lo difícil que resulta para la industria textil ecuatoriana competir con este gigante de la industria textil.

TABLA 1. IMPORTACIONES DE PRENDAS DE VESTIR SEGÚN SU ORIGEN

\begin{tabular}{|c|c|c|c|c|}
\hline \multicolumn{5}{|c|}{ Importaciones de prendas de vestir de enero a diciembre de 2015} \\
\hline Origen & Ton & Usd Cif & Usd/Kg & $\%$ Total \\
\hline China & $4.169,224$ & $\$ 37.554,03$ & $\$ 9,01$ & $45 \%$ \\
\hline Can & $1.757,585$ & $\$ 83.576,06$ & $\$ 47,55$ & $19 \%$ \\
\hline Estados Unidos & $1.246,714$ & $\$ 42.082,55$ & $\$ 33,75$ & $14 \%$ \\
\hline Panamá & 998,478 & $\$ 36.238,55$ & $\$ 36,29$ & $11 \%$ \\
\hline Mercosur & 37,868 & $\$ 1.870,63$ & $\$ 49,40$ & $0 \%$ \\
\hline Resto de Asia & 181,300 & $\$ 3.903,58$ & $\$ 21,53$ & $2 \%$ \\
\hline Resto del Mundo & 863,753 & $\$ 39.701,98$ & $\$ 45,96$ & $9 \%$ \\
\hline Total & $9.254,922$ & $\$ 244.927,36$ & $\$ 34,79$ & $100 \%$ \\
\hline
\end{tabular}


El análisis anterior se fortalece al comparar los valores de la Tabla $\mathrm{N}^{\circ}$. 1, en la cual se verifica que al año 2015 desde la China ingresaron más de 4.100 toneladas de prendas de vestir y de la CAN un valor no alcanza las 1.800 toneladas. No obstante, por la diferencia en el promedio por kilo declarado, el valor CIF de las prendas de vestir procedentes de la China (US \$9,01) bordea los US \$ 37 millones y medio, mientras que las prendas importadas de la CAN ( US $\$ 47,55$ ) superan las US $\$ 83$ millones y medio en valor CIF.

TABLA 2. IMPORTACIONES DE ROPA DE HOGAR SEGÚN SU ORIGEN

\begin{tabular}{|c|c|c|c|c|}
\hline \multicolumn{5}{|c|}{ Importaciones de ropa de hogar de enero a octubre del 2015} \\
\hline Origen & Ton & Usd Cif & Usd/Kg & $\%$ Total \\
\hline Perú & 228,831 & $\$ 973,34$ & $\$ 4,25$ & $25 \%$ \\
\hline China & 204,606 & $\$ 1.693,65$ & $\$ 8,28$ & $23 \%$ \\
\hline Colombia & 155,220 & $\$ 1.754,06$ & $\$ 11,30$ & $17 \%$ \\
\hline Panamá & 91,321 & $\$ 1.097,76$ & $\$ 12,02$ & $10 \%$ \\
\hline Chile & 72,768 & $\$ 181,61$ & $\$ 2,50$ & $8 \%$ \\
\hline Bolivia & 45,754 & $\$ 199,91$ & $\$ 4,37$ & $5 \%$ \\
\hline Resto del Mundo & 110,852 & $\$ 1.510,28$ & $\$ 13,62$ & $12 \%$ \\
\hline Total & 909,351 & $\$ 7.410,61$ & $\$ 8,05$ & $100 \%$ \\
\hline
\end{tabular}

En relación con la importación de ropa de hogar, Perú se convierte en el primer proveedor del Ecuador con un $25 \%$, mientras que China le sigue de cerca con el $23 \%$ de participación. La tendencia de los valores promedio declarados se revierte, pues desde Perú la ropa de hogar ingresa a US $\$ 4,25$ el kilo y desde la China se importa a US \$8,28 el kilo, sin embargo, al comparar con los valores promedio de Colombia y Panamá, que juntos representan el $27 \%$ de las importaciones de este rubro, resulta aún bajo, pues de estos países ingresan a US \$11,30 y US \$12,02 el kilo respectivamente.

\section{Importaciones vía Régimen de Mensajería Acelerada o Courier}

Es el envío de paquetes y/o bultos a través del Operador Público del Servicio Postal Oficial del Ecuador o de una Empresa Courier, cuyo valor no exceda del límite que se establece en el Reglamento y que serán despachados mediante formalidades simplificadas, conforme los procedimientos que establezca la Aduana del Ecuador. Los envíos o paquetes que excedan el límite establecido, se sujetarán a las normas aduaneras generales. Servicio Nacional de Aduana del Ecuador (2016, párr.1)

Los envios por dicha modalidad se clasifican en 6 categorias, en lo que respecta a los textiles y prendas de vestir confeccionadas; estos arriban a través de la categoría "B“ 4x4 (4 kilos y US \$400) y categoría "D" hasta 20 kilos y US $\$ 2000$ en valor FOB.

Según información proporcionada por el SENAE se evidencia una caída en las importaciones a través del régimen de mensajería acelerada o courier, pues de USD 118.111.871,86 que ingresaron en 2013 al amparo de la partida 9807.10.10, se redujo a USD 54.150.416,98 en 2015. Las razones para este comportamiento podrían estar relacionadas con la implementación del arancel específico de USD 42 por importación y la limitación de hasta 5 importaciones o USD $\$ 1200$ por destinatario al año. 
Figura 2. RÉGIMEN 91 / M. A.

COURIER IMPORTACIÓN - PARTIDA 9807.10.10 - ENERo 2013 - JULIO 2016 (USD)

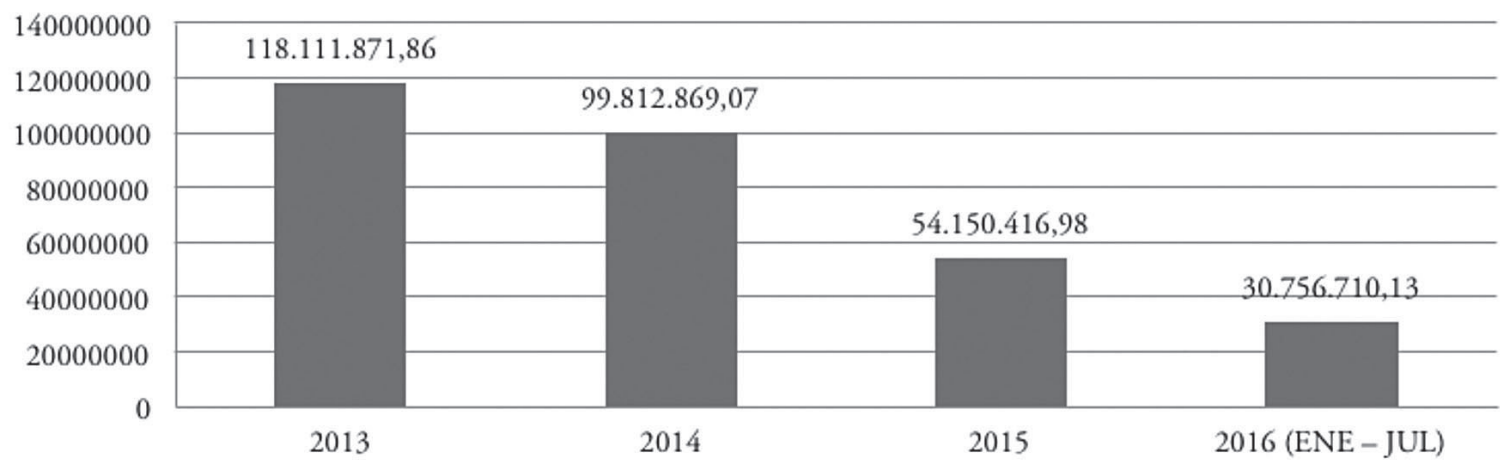

Fuente: (SENAE 7, 2016)

Figura 3. Régimen 92 / Importaciones Correos del Ecuador -

PARTIDA 9807.30.10 - ENERO 2013 - FEBRERO 2015

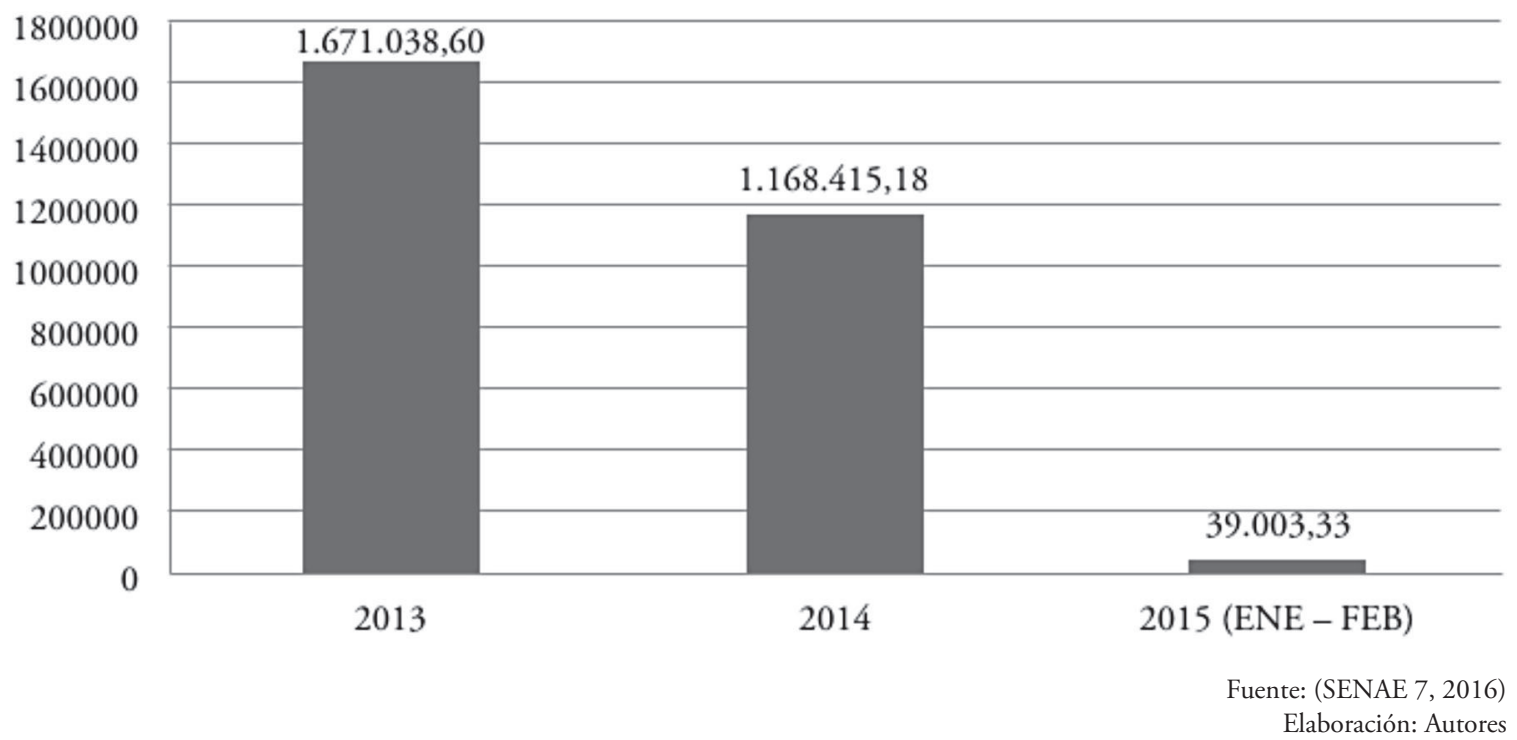

La figura precedente, corresponde a las importaciones de la categoría D y confirma la tendencia decreciente ocurrida con la categoría B. Las razones en este caso serían la exigencia de la presentación del certificado INEN - MIPRO y normas del etiquetado RT 13, a lo que se suma la aplicación de una salvaguardia de $25 \%$.
Según (SENAE 3, 2016) el incremento de aprehensiones a partir del ańo 2013 se debe a la implementación de proyectos emblemáticos en la lucha contra el contrabando como el programa de llamadas 1800-Delito, el mismo que entró en operación desde mayo del 2012, a ello se suma el empleo de cámaras de seguridad en fronteras 
Figura 4. Aprehensiones Textiles (USD)

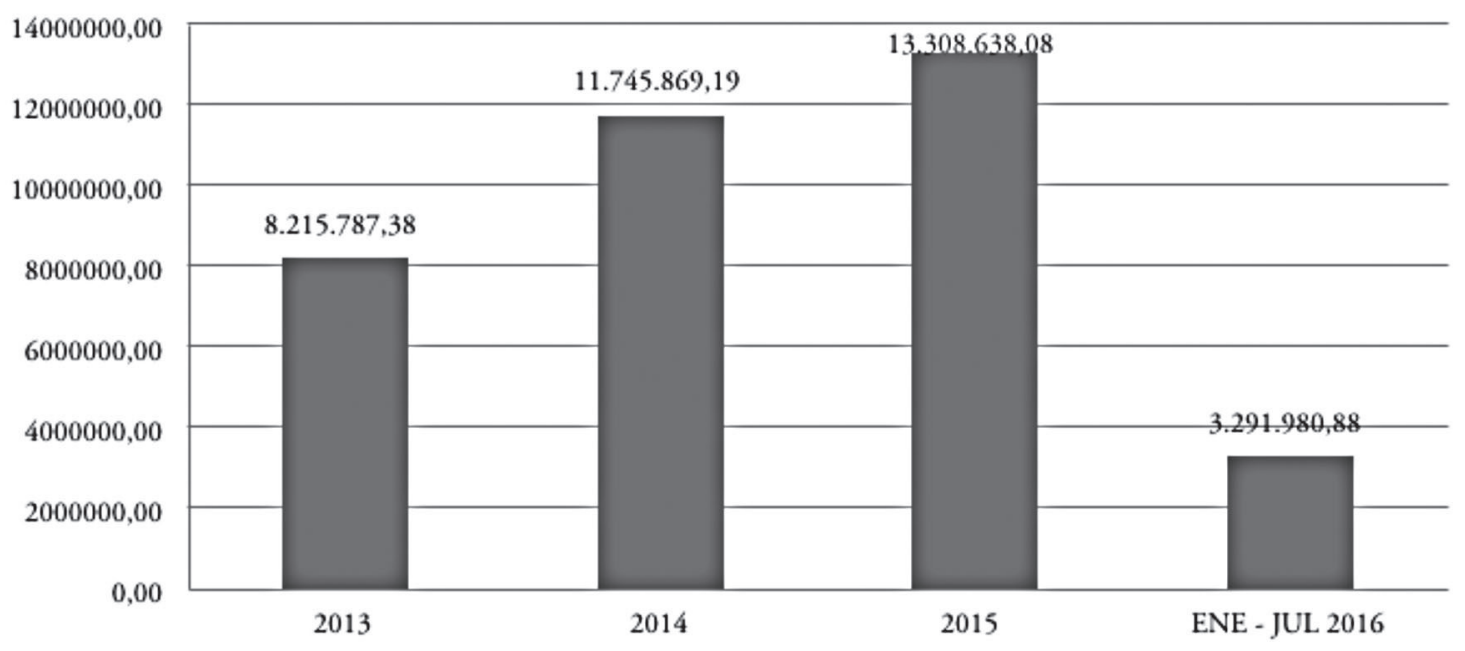

terrestres del sistema ECU 911, controles en salas y correos, máquinas de rayos $\mathrm{X}$, que fueron instaladas en la frontera sur para realizar un escaneo a vehículos privados y públicos que transitan por el lugar. Un factor adicional a ser considerado es la aplicación de salvaguardias desde inicios del 2015 a 840 subpartidas arancelarias vinculadas al ámbito textil que grabaron con porcentajes entre el 5 y $45 \%$ de sobretasa.

\section{Estrategias para el control del Fraude Aduanero}

Según (SENAE 3, 2016) del procedimiento de Control posterior realizado en año 2015, el cual es ejercido a partir del levante de las mercancías, el valor a cobrar por el SENAE asciende a USD 28.854.863,65, que básicamente corresponden a subvaloración, errores en clasificación, mal uso de régimen especial y errores en devolución de impuestos y registro de TNAN.

En lo que respecta a los operativos de control contra el contrabando, (SENAE 7, 2016) se verifica que desde el ańo 2013 hasta julio de 2016 se realizaron aprehensiones por un total de USD 36.562.276, notándose que el año 2015 es el de mayores montos incautados con un valor superior a los USD. 13 millones trecientos mil dólares. La razón podría estar en la implementación de sobretasas arancelarias a partir de marzo de ese año, a lo que se suma la vigencia del arancel específico de 5,5 dólares por cada kilo de ropa importado y la exigencia de las normas de etiquetado RT-13.

\section{Contrabando estimado de textiles}

A la cifra de US \$36.562.276 que corresponde a aprehensiones de textiles que pretendieron ingresar de manera ilegal o clandestina al Ecuador, es necesario agregar un análisis de aquella mercancía que se registra como exportada al país versus los valores que efectivamente se encuentran declarados en el rubro de importaciones del SENAE. En nuestro caso hemos seleccionado a cinco países: China, Corea del Sur, Estados Unidos, Perú, y Brasil como los países de origen, considerando 25 subpartidas del Arancel de importaciones, cinco por cada país. 
Tabla 3. Subpartidas Analizadas para el estudio de estimación del contrabando

\begin{tabular}{|c|c|c|c|c|}
\hline China & Estados Unidos & Corea del Sur & Perú & Brasil \\
\hline '540752 & '560314 & '540249 & '540244 & ‘590320 \\
\hline '590310 & ‘610459 & ‘590390 & ‘600410 & ‘600633 \\
\hline ‘590320 & ‘620990 & ‘600410 & ‘600622 & ‘610322 \\
\hline ‘600192 & ‘621710 & ‘630140 & ‘611020 & ‘610510 \\
\hline ‘610891 & ‘630900 & ‘630790 & ‘621142 & ‘621132 \\
\hline
\end{tabular}

Las partidas seleccionadas corresponden tanto a tejidos y telas como prendas y complementos de vestir y demás artículos textiles confeccionados que por sus montos exportados se constituyen en las más significativas.

Tabla 4. Exportaciones e Importaciones declaradas de textiles 2010 - 2105

\begin{tabular}{|c|c|c|c|}
\hline País & $\begin{array}{c}\text { Exportaciones a Ecuador } \\
\text { (\$ miles) }\end{array}$ & $\begin{array}{c}\text { Importaciones } \\
\text { declaradas } \\
\text { por Ecuador (\$ miles) }\end{array}$ & $\begin{array}{c}\text { Diferencia } \\
\text { (\$ miles) }\end{array}$ \\
\hline China & $\$ 223.030,00$ & $\$ 94.773,00$ & $\$ 128.257,00$ \\
\hline Perú & $\$ 67.115,00$ & $\$ 56.529,00$ & $\$ 10.586,00$ \\
\hline Estados Unidos & $\$ 28.828,00$ & $\$ 3.312,00$ & $\$ 25.516,00$ \\
\hline Corea del Sur & $\$ 14.775,00$ & $\$ 2.477,00$ & $\$ 12.298,00$ \\
\hline Brasil & $\$ 2.103,00$ & $\$ 752,00$ & $\$ 1.351,00$ \\
\hline Total & $\$ 335.851,00$ & $\$ 157.843,00$ & $\$ 178.008,00$ \\
\hline
\end{tabular}

De la tabla anterior se desprende que China es el principal exportador de textiles hacia el Ecuador con un valor registrado de US \$ 223 millones exportados de los cuales US $\$ 94$ millones se registran como importación en el SENAE, generándose una diferencia de US \$ 128 millones aproximadamente, lo que equivaldría a decir que el $58 \%$ de las exportaciones de textiles al Ecuador no se registran como tales; es de anotar que las partidas que más se comercializan correspon- den a tejidos y telas. Perú provee principalmente telas y tejidos y la diferencia alcanza un $16 \%$, pues mientras las exportaciones registran US $\$ 67$ millones, la Aduana del Ecuador reporta US \$ 56 millones ingresados. En el caso de Estados Unidos, los principales productos importados son las prendas y complementos de vestir y demás artículos textiles confeccionados, y aunque los montos comercializados son más bajos, la diferencia alcanza al $89 \%$. 
Figura N ${ }^{\circ} .5$ Diferencias entre EXPortaciones e IMportaCiones 2010 - 2015 En Miles de DÓlares

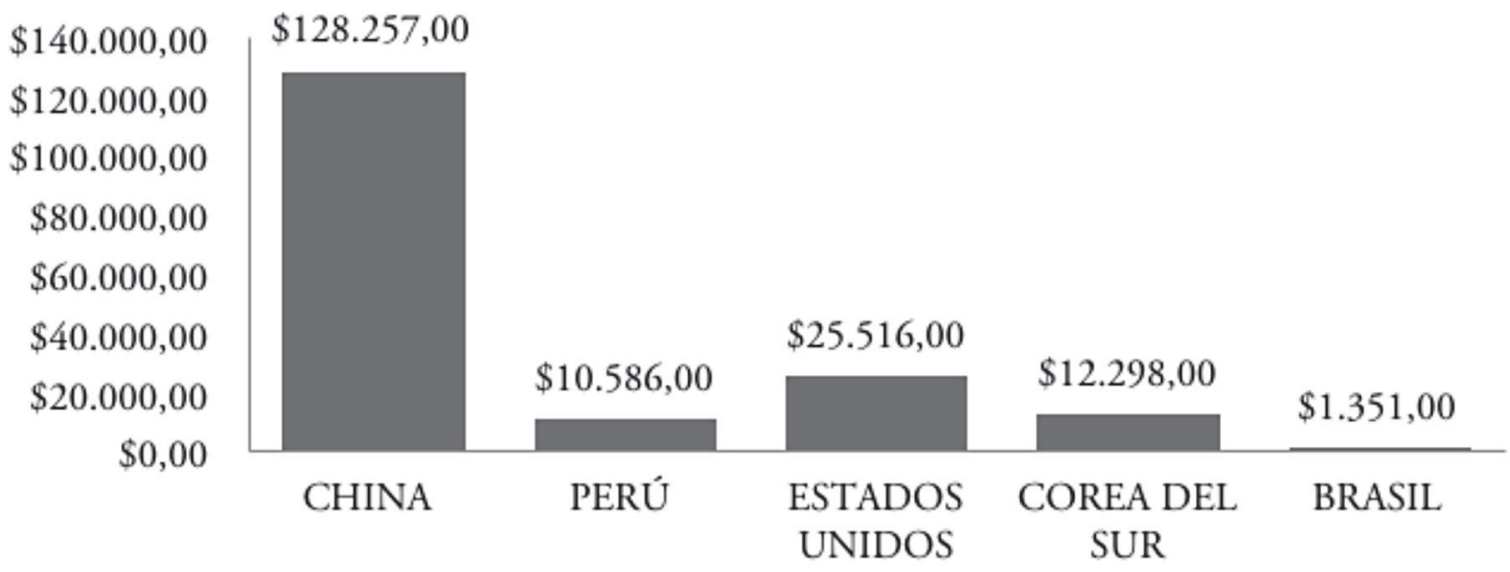

Fuente: BCE - TRADEMAP

\section{Discusión}

El contrabando y la subvaloración son las formas más frecuentes de fraude aduanero en la industria textil, que se los realiza de dos formas, una es el ingreso masivo por la frontera terrestre a través de pasos no habilitados y por vía marítima utilizando puertos clandestinos, la otra, en pequeńas cantidades o también conocido como contrabando de hormiga que ingresa a través de Salas de Arribo Internacional, Régimen de Mensajería Acelerada o Courier, Régimen de Paquetes Postales y compras que realizan las personas que cruzan la frontera terrestre con los países vecinos. Las mercancías así ingresadas, utilizan las redes sociales, "boutiques", domicilios y bahías, como sus principales formas de comercialización.

China es el principal proveedor de textiles tanto de materia prima como de confecciones, seguido de Perú que exporta básicamente los mismos productos. Los Estados Unidos en cambio, comercializa prendas y complementos de vestir y demás artículos textiles confeccionados, el denominador común con estos tres países es la diferencia que existe entre los registros de exportación de origen y los reportes de importación en Ecuador, lo cual afectaría, en primer término, con una menor re- caudación de tributos y luego, generaría competencia desleal con la industria nacional y con los importadores formales del país.

Las aprehensiones de textiles presentan una tendencia creciente durante los últimos tres años, período en el que superan los US \$ 36 millones, lo cual, más allá de mostrar la eficiencia de los controles por parte de la Aduana, evidencia la creciente informalidad que afecta negativamente al sector.

El ingreso de prendas de vestir en pequeñas cantidades utilizando el Régimen de Courier y Paquetes Postales a través de las categorías “B y D”, se lo realiza de manera frecuente lo que suma grandes cantidades que terminan como parte de la competencia desleal a la que se enfrenta la industria textil ecuatoriana, no obstante que, el arancel específico y las sobretasas arancelarias dispuestas por el gobierno han hecho que las cifras de ingreso disminuyan en un $15 \%$ entre 2014 y 2013 , y en un $46 \%$ entre 2015 y 2014 en lo que a la categoría "B" régimen "courier" se relaciona. En cuanto a la categoría "D" la disminución también es evidente ya que entre 2014 y 2013 se reduce en un 30\%, mientras que en 2015 los registros son mínimos. 


\section{Referencias bibliográficas}

- Asamblea Nacional 1. (29 de diciembre de 2010). Código Orgánico de la Producción, Comercio e Inversiones. Registro Oficial 351. Quito, Pichincha, Ecuador: Editora Nacional.

- Asamblea Nacional 2. (19 de mayo de 2011). Reglamento al Título de la Facilitación Aduanera para el Comercio, del Libro V del Código Orgánico de la Producción, Comercio e Inversiones. Registro Oficial 452. Quito, Pichincha, Ecuador: Editora Nacional.

- CAN 1. (12 de diciembre de 2003). Régimen Andino sobre Control Aduanero. DECISIÓN 574. Lima, Perú: Comunidad Andina.

- CAN 2. (12 de junio de 2000). Asistencia Mutua y Cooperación entre las Administraciones Aduaneras de los Países Miembros de la Comunidad. Decisión 478. Lima, Perú: Secretaría General CAN. Obtenido de http://intranet. comunidadandina.org/documentos/Gacetas/ Gace571.PDF

- CAN 3. (15 de diciembre de 2003). Valor en Aduana de las Mercancías Importadas. Decisión 571. Lima, Perú: Secretaría General CAN.

- CAN 4. (2007). Lucha contra el fraude. Lima, Perú: Bellido Ediciones.

- CEP. (1998). La OMC a su alcance. Quito: Corporación de Estudios y Publicaciones.

- CRAIG, V. (2013). Historia y futuro de la Organización Mundial de Comercio. Ginebra: Publicaciones de la OMC.

- GARAVITO, J. A. (2007). Control Aduanero. Lima, Perú: Bellido Ediciones.

- OMA 1. (4 de marzo de 2013). Convenio de Kyoto - Directivas del Anexo General - Capitulo 6 Control Aduanero. Obtenido de Organización Mundial de Aduanas: http://www.wcoomd.org/ en/topics/facilitation/instrument-and-tools/ conventions/pf_revised_kyoto_conv/kyoto_ new/ / media/AE00B7CE28BE44CD94 08210989EF615C.ashx

- OMA 2. (4 de marzo de 2013). Convenio de Kyoto - Directivas del Anexo General - Capitulo 7 Aplicación de la Tecnología de la Información. Obtenido de Organización Mundial de Aduanas: http://www.wcoomd.org/en/topics/ facilitation/instrument-and-tools/conventions/ pf_revised_kyoto_conv/kyoto_new/ /media/F4CB7BCA02944900A257475 58CFF98D2.ashx

- OMC. (3 de octubre de 2014). Visión general. Obtenido de Organización Mundial del Comercio: https://www.wto.org/spanish/thewto_s/ whatis_s/wto_dg_stat_s.htm

- SENAE 1. (17 de enero de 2014). Informe de Gestión 2013. Obtenido de Aduana del Ecuador: http://www.aduana.gob.ec/files/pro/leg/ tra/Informe_Gestion_2013_02.pdf

- SENAE 2. (29 de abril de 2015). Informe de Gestión 2014. Obtenido de Aduana del Ecuador: http://www.aduana.gob.ec/files/main/rendicion_cta/2014/2-a-I-InformeGestion2014.pdf

- SENAE 3. (30 de marzo de 2016). Informe de Gestión 2015. Obtenido de Aduana del Ecuador: http://www.aduana.gob.ec/files/main/rendicion _cta/2015/2-a-I-InformeGestion2015.pdf

- SENAE 4. (4 de agosto de 2016). Canal de Aforo Físico. Obtenido de Aduana del Ecuador: http://www.aduana.gob.ec/contents/popup/ pop_resultados $1 . j s p$

- SENAE 5. (4 de agosto de 2016). Canal de Aforo Automático. Obtenido de Aduana del Ecuador: http://www.aduana.gob.ec/contents/ popup/pop_resultados2.jsp

- SENAE 6. (4 de agosto de 2016). Recaudación y Tiempos. Obtenido de Aduana del Ecuador: http://www.aduana.gob.ec/contents/popup/ pop_resultados3.jsp 